\title{
Editorial
}

\section{Editorial to the Special Issue "Space Weather"}

\author{
Essam Ghamry ${ }^{1, * \mathbb{C}}$, Nurul Shazana Abdul Hamid ${ }^{2,3}$ and Zheng Li ${ }^{4}$ \\ 1 Geomagnetic Laboratory, Department of Geomagnetic and Geoelectric, National Research Institute of \\ Astronomy and Geophysics (NRIAG), Helwan 11421, Cairo, Egypt \\ 2 Department of Applied Physics, Faculty of Science and Technology, Universiti Kebangsaan Malaysia, \\ Bangi 43600, Selangor, Malaysia; zana@ukm.edu.my \\ 3 Space Science Centre, Institute of Climate Change, Universiti Kebangsaan Malaysia, Bangi 43600, \\ Selangor, Malaysia \\ 4 Institute of Space Weather, Nanjing University of Information Science \& Technology, Ningliu Road No. 219, \\ Nanjing 210044, China; zli@nuist.edu.cn \\ * Correspondence: essamgh@nriag.sci.eg
}

check for updates

Citation: Ghamry, E.; Hamid, N.S.A.; $\mathrm{Li}, \mathrm{Z}$. Editorial to the Special Issue "Space Weather". Universe 2022, 8, 59. https://doi.org/10.3390/universe 8020059

Received: 15 December 2021

Accepted: 4 January 2022

Published: 18 January 2022

Publisher's Note: MDPI stays neutral with regard to jurisdictional claims in published maps and institutional affiliations.

Copyright: () 2022 by the authors Licensee MDPI, Basel, Switzerland. This article is an open access article distributed under the terms and conditions of the Creative Commons Attribution (CC BY) license (https:// creativecommons.org/licenses/by/ $4.0 /)$.
The present Special Issue is focused on the term space weather, which has increasingly been used to describe phenomena in the near-earth space environment that impact telecommunications, transportation, electric power, satellite navigation, spacecraft design and operations, and other technologies on Earth.

Ten papers were contributed to this Special Issue; they were related to the ionospheric behavior of foF2 over the Chinese EIA Region, investigation of the periodicities of sunspot numbers and the Earth's climate change, the impact of coronal mass ejections on the seasonal variation of the ionospheric critical frequency, correlations between earthquake properties and characteristics of possible ULF, comparisons of EEJ longitudinal variation from satellite and ground measurements over different solar activity levels, statistical analysis of plasma bubbles observed by swarm, geoeffective magnetosheath plasma jets area, and fractal properties of geomagnetic northward component data (H-component) in the equatorial region and the behavior of electron temperature $(\mathrm{Te})$ at small scales in the topside ionosphere.

Starting the Special Issue with one of the most widely used global empirical models, the international reference ionosphere (IRI) was developed by the Committee on Space Research (COSPAR) and the International Union of Radio Science (URSI) to represent ionospheric variations. The IRI model plays a significant role in study of the ionosphere and the engineering application of radio wave communication and navigations. Inevitably, there are some discrepancies in foF2 and hmF2 between the empirical model of the ionosphere and observations. Therefore, many studies [1-7] of comparison between them were carried out to test the performance of the IRI, which could help to improve the accuracy of the IRI in future work. The auther of [6] summarized comparative studies of observations and IRI model from different sectors of the globe.

The auther of [8] focuses on diurnal and seasonal variations of foF2 over Chinese EIA region (Puer station, $22.7^{\circ} \mathrm{N}, 101.05^{\circ} \mathrm{E}$, Dip Latitude $12.9^{\circ} \mathrm{N}$ ) in the year 2016 . Then, a comparative study of observations and the IRI model was performed to test the performance of the IRI model over the southwest sector of China. Puer station is a newly installed ionosonde station in the Chinese EIA region along the longitude of about $100^{\circ} \mathrm{E}$; therefore, it can provide more data to improve the performance of IRI in the future.

The question of how strongly the Sun influences climate change on Earth is eternally debated, with topics ranging from the lack of evidence to contradictions. Ref. [9] adopted the largest amount of reconstruction data of sunspot numbers [10] so far to investigate the periodicities of both solar activity and temperatures of four independent stations on the Earth (three in the northern hemisphere and one in the southern hemisphere) [11-14] during the past 8640 years (BC 6755-AD 1885), as well as their cross-wavelet coherences. 
They found that all their variations had an evident 1000-year cyclicity, which had recently been discovered in solar activity (named the Eddy cycle [15]), but is rarely seen in the Earth's climate change. The cross-wavelet analysis further demonstrated that the millennial variation of sunspot number keeps in phase with variations of Lake Qinghai's temperature, Greenland's temperature, and the East Asian Monsoon, but out of phase with the variation of Antarctica's temperature. This revealed that the millennial variations of the Earth's climate presented a seesaw pattern, i.e., the two hemispheres had opposite trends, and they might be modulated by the long-term solar variation.

In order to further confirm this finding, [16] extended the sources of climate data to 10 sites [17] evenly distributed in the northern and southern hemispheres of the Earth, and obtained the same results, although the Earth's climatic response to solar forcing could be different region-by-region, and the temperatures in the southern hemisphere seemed to have an opposite changing trend compared to those in the northern hemisphere on this millennial scale. These findings reveal not only a pronounced but also a complex relationship between solar variability and climatic change on Earth on the millennial timescale. All these open up new research directions for studying the relationship between solar activity and long-term changes in the earth's climate.

Ref. [18] studied the monthly average values of f0F2 through 1996-2013 (from Puerto Rico ionosonde station) and the corresponding monthly average values of the CME's parameters. They also found that the monthly average value of fOF2 has a high coherence with the sunspot number (SSN). This behavior emphasizes that the f0F2 profiles rely on solar activity. Moreover, CME's parameters are found to be varying with SSN in the same coherence behavior, like f0F2. Ref. [18] checked the monthly correlations between the physical properties of $\mathrm{CME}$ and those of fOF2 during the same period. They found a linear correlation of approximately $0.73,0.6$ and 0.6 for the CME energy, angular width and initial speed, respectively. They conclude that the wider, energetic, and faster CMEs can increase the electron density in the ionosphere due to the plasma injection, giving rise to high values of f0F2. They also conclude that the highest impact of the CMEs on the seasonal variation is found to be in the summer, then equinoxes (spring and autumn) followed by winter.

The paper written by [19] focuses on extending the potential of geomagnetic anomalies in the ultra-low frequency (ULF) range as a possible earthquake precursor. In their study, geomagnetic field data were obtained from 10 magnetometer stations that are situated close to 34 earthquakes around the world. The temporal range of the study was limited to between the year 2007 and 2016 based on the availability of high resolution (i.e., $1 \mathrm{~Hz}$ ), which is relatively scarcer compared to lower resolution data. Their study aimed to obtain two parts of earthquake prediction, that is precursor detection and direction estimation in Southeast Asia, East Asia, and South America regions. Their paper reported that $58.82 \%$ of the studied earthquakes were preceded by geomagnetic anomalies, which were possibly the precursor to the earthquakes. When looking at the correlation between the characteristics of the possible precursors and the earthquake properties, weak correlations were obtained. However, when the study area was focused only in Japan near ONW (Onagawa) and TNO (Tohno) stations, the correlations were stronger $(r \geq 0.60, p<0.05)$. They found that the lead time of the precursor is correlated with the earthquake magnitude, the local seismicity index, and the hypocentral depth. Additionally, the error percentage of the estimated direction was somewhat correlated with the hypocentral depth. The paper concluded that correlations between earthquake properties and precursor characteristics possibly existed when the study area was restricted to a specific location.

Ref. [20] utilized long-term data from satellite and ground measurement to study the equatorial electrojet (EEJ) current dependency on longitude. They applied the normalization method towards ground magnetometer data to overcome the latitudinal variation of EEJ current before the comparison with the satellite data can be made. In all analyses conducted, they only considered quiet days' data and the data are categorized according to low, moderate and high solar activity levels. Their paper reported a good agreement between the longitudinal profiles of the EEJ currents that were measured from satellite 
and ground data during low solar activity level. In general, they summarize that those strong correlations were obtained between 11:00 and 13:00 local time (LT) in most of the sectors where ground data were available. Apart from that, this paper also suggested that the different times of maximum EEJ current appearances were seasonally dependent only at certain longitude sectors.

The equatorial plasma bubbles (EPBs) during different levels of geomagnetic storms by using seven years of Swarm data (IBI) have been studied [21]. They found that the majority of IBIs are observed within 20 latitudes around the dip equator. They found that IBI exhibited a large range of longitude during moderate and super storms, but it was found within limited longitudes over the South Atlantic Anomaly (SAA). The numbers of IBIs in the northern hemisphere are always slightly larger than their corresponding southern hemispheric numbers at all longitudes during super, intense, and moderate geomagnetic storms. During super and intense storms, the number of IBIs at the altitudes of Swarm B is larger than those observed at the altitudes of Swarm A and C. During moderate storms, the majority number of IBIs are observed by Swarm A and C. The duration time of IBIs show that it is abundant over SAA and it increases from the sunset until midnight. Moreover, they found that the seasonal variations of IBIs indicated that the numbers of IBIs in the equinoxes are always larger than those in the summer and winter months. Furthermore, the number of IBIs has two crests: one at 20:00 LT and the other at 22:00 LT during months 9-11. COSMIC electron density at the F2 layer peak height (hmF2) layer showed that, during super storms, the electron density data are dramatically decreased/depleted in comparison with moderate and intense storms.

The next paper is a preliminary study of an important area that affects the spaceweather around the Earth, called magnetosheath plasma jets [22], This paper studied four mechanisms of magnetosheath plasma jet that interact with the magnetopause using the Time History of Events and Macroscale Interactions during Substorms (THEMIS) during the years 2007 to 2009 . Additionally, the paper made a statistical survey of 554 such geoeffective jets. They showed that a major portion $(69 \%)$ of these jets were produced by directional discontinuities. They also found that the fastest and strongest jets that impact the Earth's magnetopause arise from the rotational discontinuities.

The paper of [23] presents the fractal properties of geomagnetic data in the equatorial region of Southeast Asia during low, intermediate and high phases of solar activity using the Hurst exponent $(\mathrm{H})$ as the parameter. In particular, they utilized the geomagnetic northward component data (H-component) obtained from two magnetometer stations of Langkawi, Malaysia (LKW) and Davao, Philippines (DAV). Their paper had three scopes: one was to identify fractal signatures in long term geomagnetic data, the second was to find the most accurate fractal method to be used with geomagnetic data, and the third was to analyze various short and long-term cases of geomagnetic quiet and disturbed days using the best fractal method. They found that the fractal signatures in long term geomagnetic data from the Southeast Asian region have virtually the same fractal signatures as the geomagnetic data from other equatorial regions, such as South America and Africa. Their analysis also demonstrated that the DFA method is still the best method for quantifying geomagnetic data, far outclassing the newer method of r-DFA. Lastly, their quantitative analysis shows that short term $\mathrm{H}$-component data of quiet days have anti-persistence tendencies $(\mathrm{H}<0.5)$ while disturbed days have persistence tendencies $(\mathrm{H}>0.5)$. As for the long-term H-component data, both quiet and disturbed days show random tendencies, with disturbed days generally having higher Hurst exponent values compared to quiet days. Their paper concluded that the Hurst exponent, when utilized with H-component data, may hold the potential to be a geomagnetic storm monitoring tool in the Southeast Asian region.

The last paper in this Special Issue demonstrated a statistical study of the rate of change of electron temperature index (ROTEI) [24], ROTEI provides a description of the small-scale variations of the electron temperature (Te) along the Swarm satellite's orbit. The main target is to characterize the mean spatial, diurnal, seasonal, and solar activity 
variations exhibited by small-scale Te variations in the topside ionosphere through in situ observations collected by Langmuir Probes on board the European Space Agency Swarm satellites from the beginning of 2014 to the end of 2020. The findings of the paper are: (1) the presence of very high ROTEI values at high latitudes all throughout the day, and at mid and low latitudes for the MLT sectors around 9:00 and 15:00; (2) ROTEI exhibits a distinct day/night diurnal trend at low and mid latitudes, which is instead quite negligible at high latitudes; (3) high latitudes exhibit a large seasonal variation with the highest ROTEI values in winter and lowest in summer, while at mid and low latitudes the seasonal dependence is weaker; (4) ROTEI exhibits a faint solar activity dependence with slightly higher values at low solar activity.

Funding: Nurul Shazana Abdul Hamid is supported by the grant FRGS/1/2018/STG02/UKM/02/3 of Ministry of Higher Education Malaysia. Zheng Li is supported by the National Natural Science Foundation of China (42074183).

Conflicts of Interest: The authors declare no conflict of interest.

\section{References}

1. Batista, I.S.; Abdu, M.A. Ionospheric variability at Brazilian low and equatorial latitudes: Comparison between observations and IRI model. Adv. Space Res. 2004, 34, 1894-1900. [CrossRef]

2. Zhang, M.L.; Shi, J.K.; Wang, X.; Wu, S.Z.; Zhang, S.R. Comparative study of ionospheric characteristic parameters obtained by DPS-4 digisonde with IRI2000 for low latitude station in China. Adv. Space Res. 2004, 33, 869-873. [CrossRef]

3. Chuo, Y.J.; Lee, C.C. Ionospheric variability at Taiwan low latitude station: Comparison between observations and IRI-2001 model. Adv. Space Res. 2008, 42, 673-681. [CrossRef]

4. Yadav, S.; Dabas, R.S.; Das, R.M.; Upadhayaya, A.K.; Sharma, K.; Gwal, A.K. Diurnal and seasonal variation of F2-layer ionospheric parameters at equatorial ionization anomaly crest region and their comparison with IRI-2001. Adv. Space Res. 2010, 45, 361-367. [CrossRef]

5. Zhao, X.; Ning, B.; Zhang, M.L.; Hu, L. Comparison of the ionospheric F2 peak height between ionosonde measurements and IRI2016 predictions over China. Adv. Space Res. 2017, 60, 1524-1531. [CrossRef]

6. Rao, S.S.; Chakraborty, M.; Pandey, R. Ionospheric variations over Chinese EIA region using foF2 and comparison with IRI-2016 model. Adv. Space Res. 2018, 62, 84-93. [CrossRef]

7. Liu, Z.; Fang, H.; Weng, L.; Wang, S.; Niu, J.; Meng, X. A comparison of ionosonde measured foF2 and IRI-2016 predictions over China. Adv. Space Res. 2019, 63, 1926-1936. [CrossRef]

8. Zhu, P.; Xie, C.; Jiang, C.; Yang, G.; Liu, J.; Li, Z.; Zhao, Z. Ionospheric Behavior of foF2 over Chinese EIA Region and Its Comparison with IRI-2016. Universe 2020, 6, 122. [CrossRef]

9. Zhao, X.H.; Soon, W.; Velasco Herrera, V.M. Evidence for solar modulation on the millennial-scale climate change of Earth. Universe 2020, 6, 153. [CrossRef]

10. Wu, C.J.; Usoskin, I.G.; Krivova, N.; Kovaltsov, G.A.; Baroni, M.; Bard, E.; Solanki, S.K. Solar activity over nine millennia: A consistent multi-proxy reconstruction. Astron. Astrophys. 2018, 615, A93. [CrossRef]

11. Petit, J.R.; Jouzel, J.; Raynaud, D.; Barkov, N.I.; Barnola, J.M.; Basile, I.; Bender, M.; Chappellaz, J.; Davis, J.; Delaygue, G.; et al. Climate and atmospheric history of the past 420,000 years from the Vostok ice core, Antarctica. Nature 1999, 399, $429-436$. [CrossRef]

12. Stuiver, M.; Grootes, P.M. GISP2 oxygen isotope ratios. Quat. Res. 2000, 53, 277-284. [CrossRef]

13. Wang, Y.J.; Cheng, H.; Edwards, R.L.; He, Y.Q.; Kong, X.G.; An, Z.S.; Wu, J.Y.; Kelly, M.J.; Dykoski, C.A.; Li, X.D. The Holocene Asian monsoon: Links to solar changes and north Atlantic climate. Science 2005, 308, 854-857. [CrossRef] [PubMed]

14. Hou, J.; Huang, Y.; Zhao, J.; Liu, Z.; Colman, S.; An, Z. Large Holocene summer temperature oscillations and impact on the peopling of the northeastern Tibetan Plateau. Geophys. Res. Lett. 2016, 43, 1323-1330. [CrossRef]

15. Eddy, J.A. The Maunder minimum. Science 1976, 192, 1189-1202. [CrossRef] [PubMed]

16. Zhao, X.H.; Soon, W.; Velasco Herrera, V.M. Holocene Millennial-Scale Solar Variability and the Climatic Responses on Earth. Universe 2021, 7, 36. [CrossRef]

17. Marcott, S.A.; Shakun, J.D.; Clark, P.U.; Mix, A.C. A reconstruction of regional and global temperature for the past 11,300 years. Science 2013, 339, 1198-1201. [CrossRef]

18. Farid, H.M.; Mawad, R.; Ghamry, E.; Yoshikawa, A. The Impact of Coronal Mass Ejections on the Seasonal Variation of the Ionospheric Critical Frequency fOF2. Universe 2020, 6, 200. [CrossRef]

19. Yusof, K.A.; Abdullah, M.; Hamid, N.S.A.; Ahadi, S.; Yoshikawa, A. Correlations between Earthquake Properties and Characteristics of Possible ULF Geomagnetic Precursor over Multiple Earthquakes. Universe 2021, 7, 20. [CrossRef]

20. Ismail, W.N.I.; Hamid, N.S.A.; Abdullah, M.; Yoshikawa, A.; Uozumi, T.; Radzi, Z.M. Comparison of EEJ Longitudinal Variation from Satellite and Ground Measurements over Different Solar Activity Levels. Universe 2021, 7, 23. [CrossRef] 
21. Hussien, F.; Ghamry, E.; Fathy, A. A Statistical Analysis of Plasma Bubbles Observed by Swarm Constellation during Different Types of Geomagnetic Storms. Universe 2021, 7, 90. [CrossRef]

22. Dmitriev, A.V.; Lalchand, B.; Ghosh, S. Mechanisms and Evolution of Geoeffective Large-Scale Plasma Jets in the Magnetosheath. Universe 2021, 7, 152. [CrossRef]

23. Rifqi, F.N.; Hamid, N.S.A.; Rabiu, A.B.; Yoshikawa, A. Identification of Fractal Properties in Geomagnetic Data of Southeast Asian Region during Various Solar Activity Levels. Universe 2021, 7, 248. [CrossRef]

24. Pignalberi, A.; Coco, I.; Giannattasio, F.; Pezzopane, M.; De Michelis, P.; Consolini, G.; Tozzi, R. A New Ionospheric Index to Investigate Electron Temperature Small-Scale Variations in the Topside Ionosphere. Universe 2021, 7, 290. [CrossRef] 